\title{
Protecting products versus platforms
}

\author{
Jacob S Sherkow \\ Choosing an IP protection regime depends on the type of company you are building.
}

\begin{abstract}
Datents have long been the most important legal assets of biotech companies. Increasingly, however, biotech firms find themselves on one side of a divide: as either traditional product companies or platform companies. Given the differences between these two types of business models, the merits of intellectual property (IP) protection vary between them. This article explores how those differences relate to biotech startups and entrepreneurs seeking to protect their inventions.
\end{abstract}

\section{Patents and trade secrets}

Biotech companies have traditionally sought to secure their intellectual assets using one of two forms of IP: patents or trade secrets. Patents are a time-limited, government-granted property right. They prohibit others from making, using or selling the invention claimed in the patent during its term-currently in the United States, 20 years from the date it is filed with the US Patent and Trademark Office (PTO).

For several reasons, it is important to decide early on in the development process whether to protect a piece of innovation with patents or as trade secrets. For patents, companies can stake an early claim to new and useful technologies by filing provisional patent applicationsoften, simply, a rough, written description of the invention. Should priority disputes arise between competing inventions, a provisional application has the added advantage of proving that an inventor was the first to file a patent on the described technology.

After filing a provisional patent application, an inventor has one year to file a full, or complete, patent application. That application must claim, in specific terms, the invention sought to be patented. The claims then undergo examination at the PTO. The Office ensures that the claimed invention is new, useful and

Innovation Center for Law and Technology, New York Law School, New York, New York, USA.

e-mail:jacob.sherkow@nyls.edu "nonobvious." In addition, the application itself must enable others to make and use the invention and must wholly disclose, to the public, the invention sought to be patented.

Inventors who believe competitors have reproduced or used their invention can enforce their patents through the courts by suing for patent infringement. Although filing patents with the PTO is typically inexpensive-at median, roughly $\$ 10,000$, in addition to a few thousand in maintenance fees-enforcing them often costs millions. A patent infringement lawsuit concerning a product that generates at least $\$ 25$ million per year in revenue-a level easily obtained by successful biotech products-will cost almost \$7 million in attorneys' fees ${ }^{1}$. At the same time, litigation often risks the validity of the patent sought to be enforced. If a court finds, despite the PTO's examination, either that the application failed to properly disclose the invention or that the patent is not new, lacking in utility or obvious, the patent must be invalidated-an occurrence that happens in $43 \%$ of litigated cases ${ }^{2}$. Patents, therefore, are costly, high-risk/high-reward intellectual assets for biotech companies.

In contrast, trade secrets are cheap, lowrisk/low-reward forms of protection (Table 1). Trade secrets do not require any form of assessment before a government agency. Rather, they are simply any information that "derives independent economic value" as a secret and is subject to reasonable efforts to keep it so $^{3}$. These reasonable efforts may include requiring users or employees to sign confidentiality agreements to keep the invention secret. Or it may simply include a company's refusal to disclose the particulars of the invention to the public. Owners of trade secrets may enforce them against competitors when it appears that their rivals have learned about them through "improper means"-theft, bribery, misrepresentation, and so on.

Consequently, and unlike patents, trade secrets remain indefinitely enforceable until they are disclosed. This is famously illustrated by Coca-Cola's enduring 130-year-old-and counting-secret formula ${ }^{4}$, and perhaps less famously illustrated in the biotech context by Wyeth's 75-year-old-plus secret manufacturing process for Premarin from mare urine $e^{5}$. Trade secrets are also enforced through the courts, and although it certainly is not cheap, it tends to be less costly than patent litigation.

Generally, patents and trade secrets are mutually exclusive. Because patents require inventors to disclose their invention to the public, and trade secrets demand inventors engage in efforts to keep them clandestine, the same invention cannot be protected by both a patent and a trade secret. Nonetheless, many successful companies parcel complex inventions into patentable and secret elements. For example, a company developing liquid biopsy technology — an assessment of patients' cells from a small sample of fluid tissue-may protect the biopsy device with patents, but the process and software for analyzing samples, with trade secrets.

In addition to patents and trade secrets, biotech companies have also made use of data exclusivity - the right of a company to refuse to share data from clinical trials. Although not traditionally thought of as a form of IP, data exclusivity operates much like patents: a government-sanctioned freedom from competition for a fixed period of time. Currently, new drugs not including biologics receive five years of data exclusivity from the US Food and Drug Administration (FDA), during which generic manufacturers may not use those drugs' underlying clinical trial data to receive FDA approval ${ }^{6}$. Biologics, by contrast, receive 12 years of exclusivity from biosimilars ${ }^{7}$. These exclusivities come into force immediately upon FDA approval; like trade secrets, they do not require independent examination. But, because data exclusivities require a product to be approved by the FDA, and because they are typically shorter in duration than either patents or trade secrets, they remain largely 
Table 1 Patent or trade secret?

\begin{tabular}{llll} 
& Patent & Trade secret & Regulatory exclusivities \\
\hline Cost to obtain & $\$ 10,000-\$ 30,000$ & Free & Millions of dollars \\
\hline Cost to maintain & $\$ 3,150-\$ 12,600$ & $\$ 1,000$ to tens of thousands & Free \\
\hline Ease of obtaining & Medium & Easy & Hard \\
\hline Duration & 20 years from date of filing & Potentially forever & $3-12$ years \\
\hline Likelihood of loss & Medium & High & Low \\
\hline Breadth of protection & Medium to high & Low to medium & Low \\
\hline Cost of enforceability & $\$ 500,000-\$ 10$ million & $\$ 100,000-\$ 2$ million & Free \\
\hline Ease of proving infringement & Medium & Difficult & Easy
\end{tabular}

a secondary form of IP protection for earlystage biotech companies.

\section{Products versus platforms}

Historically, biotech companies have focused on developing and receiving regulatory approval for a single product, directed to treat one or a narrow group of indications. The geneses of many now-large biotech companies serve as excellent examples. Genentech's (S. San Francisco, CA, USA) first product was Protropin (somatrem), a recombinant growth hormone indicated for certain types of dwarfism. Amgen (Thousand Oaks, CA, USA) got its start by marketing Epogen (epoetin alfa), recombinant erythropoietin indicated for anemia. And Gilead's (Foster City, CA, USA) origins center on Viread (tenofovir), the antiretroviral used to treat HIV. These, and other companies like them, are product biotech companies-companies that seek to develop a specific therapeutic product to be sold directly to patients. Because of concentrations of expertise in a particular area, product biotechs tend to focus their development efforts on a single disease or disease indication. In addition, these products tend to consist of treatments themselves rather than diagnostics. At the same time, product biotech companies do not appear to be limited to certain classes of therapeutics: small-molecule therapeutics, vaccines and complex biologics all fit within the product company framework in biomedicine.

Many biotech startups, however, also develop as platform biotechs-companies seeking to develop technological platforms that can be used for a variety of conditions. These can consist of laboratory diagnostics, testing devices, or broader therapeutic protocols or modalities, such as particular forms of gene therapy. Several notable and recently established biotech companies appear to fit more firmly in this framework. Editas Medicine (Cambridge, MA, USA), Caribou Biosciences (Berkeley, CA, USA) and CRISPR Therapeutics (Cambridge, MA, USA), for example, are all focused on developing a variety of therapies ultimately grounded in a single gene-editing technology, CRISPR. Oxford Nanopore (Oxford, UK) has developed an electronic nanopore-based DNA-sequencing technology, useful for gene sequencing.

The dichotomy between product and platform is not absolute. Some companies appear to straddle the boundaries between product and platform biotechs. Stemcentrx (S. San Francisco, CA, USA), for example, has focused its development efforts on specific monoclonal antibodies used to target cancer stem cells-a development pathway much in the traditional mold of product biotech companies. But the company is using such trials to investigate the larger phenomenon of how stem cells operate across a variety of cancers in a variety of tumors. In that sense, Stemcentrx could be considered a platform biotech company as well. Similarly, Sequenom (San Diego) has developed a matrix-assisted laser desorption ionization time-of-flight mass spectrometry platform to validate gene variants from its sequencing tests but the company also develops and markets specific diagnostics for prenatal diseases and malignancies.

\section{Product and platform IP strategy}

Product and platform biotechs operate in vastly different regulatory and development spaces. Notably, FDA regulation operates differently for product and platform biotechnologies. Products primarily fall under the legal umbrella of drugs, biologics, or devices, classes of therapeutics that must receive some form of premarket approval from the FDA before commercialization. Platform technologies, on the other hand, have traditionally been characterized as laboratory-developed tests, a class of product that-to date-the FDA has been more lenient in regulating. Currently, such tests do not need premarket approval from the FDA.

Aside from these regulatory differences, development cycles between product and platform biotech also differ. Product companies often develop a single therapeutic-a specific monoclonal antibody, for example-that requires advance input from the FDA regarding the structure of surrounding clinical trials.
As a result, there is little opportunity to develop an improved or alternative version of the product without restarting the approval process. Platform technology, however-without substantial regulatory constraints-can rapidly go through phases of design, test, and build.

As a consequence of these differences, entrepreneurs should be aware of the pros and cons of certain forms of IP protection for product and platform biotech startups.

Patents. A tremendous amount of value for product companies is often tethered to the products' exclusivity. In the small-molecule drug context, for example, pioneer products can lose $>80 \%$ of their value upon the entry of five or more competitors ${ }^{8}$. Patents, more than other forms of IP, tend to provide that exclusivity to products.

This exclusivity operates in two ways. First, with respect to small-molecule drugs, patents present major stumbling blocks to competitors' pathways for FDA approval. According to the 1984 Drug Price Competition and Patent Term Restoration Act-more popularly known as the Hatch-Waxman Act-the FDA cannot approve, for at least 30 months, any generic version of a brand manufacturer's patented product that has not successfully invalidated, or proven to not infringe on, the originator's patents 9 . To that end, because patents are tethered to regulatory approval, small-molecule product companies seeking to shield themselves from generic competition will depend almost entirely on the existence of patents covering the drug, its formulation or methods of use.

Second, patents covering a pioneering product provide strong disincentives to generic competitors from launching during the product's patent term. As mentioned, the cost of patent litigation is itself exorbitant. Litigation costs aside, the harm of losing patent infringement suits can be severe. Generic competitors who launch 'at risk' face the prospect of being entirely prohibited from entering the market during the patent term. In addition, they may have to pay damages to their pioneering rivals. For example, in one patent dispute 
concerning the drug Protonix (pantoprazole), generic manufacturer Teva (Petach Tikva, Israel) agreed to settle its patent dispute with Pfizer (New York) for $\$ 2.15$ billion $^{10}$.

The advantages of patent protection are less clear for platform biotechs. Because the platform technology itself, as opposed to any products derived from the technology, will not typically require FDA premarket approval, patents do not operate in the platform space as complements to regulatory barriers. In addition, because platform technologies tend to be more complex than products from a patentclaiming perspective, competitors may find it easier to develop technologies that work around pioneer patents. For example, the patents covering Illumina's (San Diego) MiSeqDx clinical gene sequencing platform did little to prevent ThermoFisher (Waltham, MA, USA) from introducing its clinical sequencer, the Ion Chef Instrument, or Qiagen (Hilden, Germany), its GeneReader. Similarly, the patent portfolio of Stemcentrx will likely do little to stave off potential competitors.

To be sure, many notable platform companies, including Editas and Oxford Nanopore, have robust patent portfolios. But this diversity in patent protection is likely a function of the specific type of underlying technology itself, rather than the regulatory or legal landscapes in which platform companies operate. It appears that the broader and more robust the technology, the more patents will likely provide cover from competition. Fundamental technologies, such as CRISPR, may at least initially require some broad-based patents to quell competition because the underlying science is well-known, easily copied, and adaptable to a variety of physical embodiments. Specific applications of CRISPR are, even in its nascency, adaptable to a variety of systems. The corollary, however, is that the more that platform technologies are tied to particular machinery, the less patents serve as a bulwark against competitors; patents on specific machinery are often too narrow to be of value. The robust diversity of next-generation sequencing technologies seems to demonstrate this. Platform technologies dependent on particular physical technologies will likely have to compete on price, quality, and marketing - not the scientific elegance of the technology itself ${ }^{11}$.

Trade secrets. Compared with patents, trade secrets figure much less into a typical product biotech's IP portfolio. Most small-molecule drugs can be easily manufactured once their chemical structure is known; there are few things about chemical synthesis worth keeping secret. Biologics, however, do present a clear exception to this rule in the product biotech space. Because of the complexity of producing biologics, companies often go out of their way to guard the specifics of their manufacturing and scale-up methods as trade secrets. Although the active moieties themselves can sometimes be reconstructed, current analytical methods make comparing a follow-on biologic to a reference biologic troublesome. As a consequence, biosimilar manufacturers must develop their own methods of manufacture and validation, often at great expense. Related to this, the FDA cannot approve 'biosimilars' without rigorous assessments of their manufacturing methods. Product biotechs developing large, complex biologicslike monoclonal antibodies-can heavily rely on trade secrets to ensure exclusivity ${ }^{12}$.

For platform technologies, trade secrets are potentially their most powerful form of IP. Like biologics, platform technologies that generate therapeutics can keep, as trade secrets, their methods of creation, manufacture, and validation. Competitors may know only the broadest contours of their processes. And even where these processes are well known, platform companies' employees' tacit knowledge about scaling up such technology for industrial operation may serve as significant barriers to competitors ${ }^{13}$.

Similarly, platform technologies that employ complex, analytical software in their products or services, such as those of diagnostics companies, can often rely on trade secrets to shut out serious competition. Because analytical software is difficult to replicate, competitors seeking to replicate a pioneer company's testing methods or devices may nonetheless be incapable of providing comparable data analysis ${ }^{14}$. Where trade secrecy in analytical software is paired with specialized devices, platform technology companies can essentially create a black box in which few competitors can hope to operate. Indeed, this sort of combination device-software trade secrecy is precisely what originally drove valuations for Theranos ${ }^{15}$.

Data secrecy. Lastly, 'data secrecy'-in the form of both regulatory exclusivities and trade secrets-can be similarly valuable to both product and platform biotechs. Products, or platforms that generate products, requiring FDA approval benefit greatly from being able to hide information obtained during clinical trials from competitors. As a result, where premarket approval is otherwise required, competitors wishing to enter the same market as pioneer manufacturers must submit their own, costly clinical data. In many instances-such as with the requirement that biosimilars must demonstrate no "clinically meaningfully differences" to their reference drugs-this form of data secrecy appears to be a powerful disincentive for competition ${ }^{16}$.
Both product and platform technologies may also generate data themselves, such as sequencing data or reports from diagnostics. Both product and platform companies are free to keep such data confidential. Indeed, in some instances, the patient privacy regulations of the Health Insurance Portability and Accountability Act may require them to do so. Developing a robust data set concerning patient data, treatment and outcomes-a form of IP unto itself-may provide an early entrant important first-mover and exclusivity advantages over competitors. This is perhaps best illustrated by Myriad Genetics' (Salt Lake City, UT, USA) database of genetic variants. Efforts to reproduce such databases, although possible, are nonetheless arduous, and diagnostic companies can leverage such data-and their competitors' lack of it-in building brand loyalty among clinicians ${ }^{17}$.

\section{Developing your IP portfolio}

Keeping the above points in mind, consider below a few pieces of practical advice concerning IP protection for your biotech startup.

First, think about your company in the future, not necessarily as it exists during the present. IP protection is often irretrievable. Information disclosed in a patent cannot be later protected by trade secrets; information kept as a trade secret for a long enough period of time usually cannot later mature into a patent. Plan for your company's IP needs when it needs it the most-when your technology is on the market.

Second, think about the saleable unit of what you're trying to develop-and whether it can be used for other indications. Is it a drug that appears useful to treat only a single condition? Is it a machine that can diagnose a variety of ailments? Is it a technique for developing personalized therapies for a specific disease? Tackling that question may make clear whether your company is in the business of a defined product or a broad-based platform.

Third, if your venture is more product focused, think about getting early patents on the specific product itself and, potentially, formulations and methods of using it. Patents may provide some shelter from competition after you push your product through regulatory approval. If the product is difficult to manufacture-if it requires lesser-known technical know-how, or if there are differences between manufacturing it on clinical-trial and industrial scales-think about keeping that knowledge secret, as many successful biologics companies currently do. Patents on these methods won't necessarily prevent generic approval, and trade secrets in this area are more likely to stave off economically meaningful competition. 
Fourth, if your venture is more platform focused, think about keeping as much secret as possible. Try to convince outside users, testers, and developers of your technology to sign appropriate confidentiality agreements, drafted by a lawyer. In addition, don't disclose too many of the technical details of your technology in investor pitches, scientific publications, or public talks. Try to keep the inner workings of your platform secret. By contrast, if your platform focuses on a device that can be easily reverse engineered-like a desktop sequencer-it may be worth applying for patents on your technology's basic outline. But keep in mind that such patents won't be worth too much. If the patents are drafted too broadly, they're likely to be invalidated in an infringement trial. If the patents are drafted too narrowly, they'll be easily worked around by your competitors.

Finally, if your product generates data itself-for example, a diagnostic test productthink ahead about mechanisms to use that data, either as a proprietary platform or as a licensed database that you can separately monetize. If you are later faced with competition from competing services, clinicians may choose your product over your competitors' because of your head start in data aggregation.

\section{Conclusion}

Product and platform biotech companies, despite their similarities, operate in substantially different spaces with respect to regulation and IP. Patents, trade secrets and data exclusivities each benefit product and platforms differently. Patents, for example, will continue to be critical to the development of product biotechnologies across therapeutic classes. But trade secrets are likely to be of critical importance for newly developing platform technologies. Relatedly, data exclusivities of various formsfrom regulatory exclusivities to data secrecywill continue to be advantageous forms of IP for both types of companies. Biotech companies seeking to shield themselves from competition should assess how their core technologies fit within this IP framework.

\section{COMPETING FINANCIAL INTERESTS}

The author declares no competing financial interests.
1. American Intellectual Property Law Association. 2015 Report of the Economic Survey (AIPLA, 2015).

2. Allison, J.R., Lemley, M.A. \& Schwartz, D.L. Tex. Law Rev. 92, 1769-1801 (2014).

3. American Law Institute and The National Conference of Commissioners on Uniform State Laws. Uniform Laws Annotated 14, 536-659 (Thomson West, 2005).

4. Coca-Cola Bottling Co. of Shreveport, Inc. v. Coca-Cola Co., 107 F.R.D. 288 (D. Del. 1985).

5. Price, W.N. Boston Coll. Law Rev. 55, 491-562 (2014).

6. 21 U.S.C. $\$ 355(\mathrm{j})(5)(\mathrm{F})(\mathrm{ii})$

7. 42 U.S.C. $\$ 262(k)(7)(A)$.

8. Wiggins, S.N. \& Maness, R. Econ. Inq. 42, 247-263 (2004).

9. 21 U.S.C. § $355(\mathrm{j})(5)(B)(i i i)$.

10. Pearson, S., Decker, S. \& Voreacos, D. Bloomberg Business http://www.bloomberg.com/news/articles/2013-06-12/pfizer-gets-2-15-billion-settlementfrom-teva-sun-on-protonix (12 June 2013).

11. Sherkow, J.S. \& Scott, C. Nat. Biotechnol. 32, 620 (2014).

12. Price, W.N. \& Rai, A. lowa Law Rev. 101, 101-142 (2016).

13. Lee, P. Calif. Law Rev. 100, 1503-1572 (2012).

14. Nekrutenko, A. \& Taylor, J. Nat. Rev. Genet. 13, 667672 (2012)

15. Ioannidis, J.P.A. J. Am. Med. Assoc. 313, 663-664 (2015).

16. Heled, Y. The Biologics Price Competition and Innovation Act (BPCIA): a failed experiment, sham, or an exercise in futility? Intellectual Property Scholars Conference, De Paul College of Law, Chicago (7 August 2015).

17. Conley, J.M., Cook-Deegan, R. \& Lázaro-Muñoz, G. N. C. J. Law Technol. 15, 597-637 (2014). 